\title{
Biomedical Engineering Students Gain Design Knowledge and Report Increased Confidence When Continually Challenged with Integrated Design Projects
}

\section{Dr. Steven Higbee, Indiana University Purdue University, Indianapolis}

Steve is a Clinical Assistant Professor of Biomedical Engineering at Indiana University-Purdue University Indianapolis. He received his PhD in Bioengineering from Rice University (Houston, TX) in 2013, after earning his BS and MS degrees from Purdue University (West Lafayette, IN). His current position focuses on teaching, advising, and promotion of undergraduate research.

\section{Dr. Sharon Miller, Indiana University Purdue University, Indianapolis}

Dr. Miller is the Undergraduate Program Director and Clinical Associate Professor of Biomedical Engineering at Indiana University-Purdue University Indianapolis (IUPUI). After earning her BS in Materials Science and Engineering from Purdue University (West Lafayette), she earned her MS and PhD degrees at the University of Michigan (Ann Arbor). Her current roles include teaching, assisting in program assessment, student advising, and helping oversee undergraduate curriculum development and enhancement. 


\title{
Biomedical Engineering Students Gain Design Knowledge and Report Increased Confidence When Continually Challenged with Integrated Design Projects
}

\begin{abstract}
Introduction: The undergraduate biomedical engineering (BME) curriculum should prepare students to confidently approach complex problems, as graduates will enter the workforce in an environment of rising healthcare costs, decreasing average life expectancy, and significant socioeconomic disparities in health outcomes. With this landscape, solutions to contemporary problems will require innovative thinking and groundbreaking medical technologies, suggesting that the future of BME will be increasingly design-oriented. BME curricula generally include laboratory and project components aimed at preparing students for senior capstone; however, students may begin capstone without the knowledge, skills, and confidence required for engineering design success. With these shortcomings in mind, we integrated design experiences across our BME curriculum and evaluated student design performance throughout.
\end{abstract}

Methods: Four engineering design project assignments were developed and integrated into sophomore- and junior-level BME laboratory courses, establishing a continuous design thread in the curriculum. Through the sequence of projects, student teams worked to design (1) fracture fixation plates, (2) electromyogram-controlled motor systems, (3) compact spectrophotometers, and (4) drug dosing devices. We also developed a common instructional Design Module and used it in each course to build student understanding of the BME design process. The set of design projects targeted a multitude of technical skills relevant to design, including computeraided design (CAD), computational modeling, iteration, prototyping, programming, hardwaresoftware integration, and technical communication. A mixed methods approach was employed to assess student knowledge, confidence, and achievement in design. A pre-/post-quiz was used to assess student knowledge of design concepts and their application toward medical device design. Students self-reported their design confidence levels prior to the first design project and after each design project, and focus groups were held after design projects to assess student design confidence going forward. Students also rated how worthwhile and enjoyable they found each project and reflected on the integration of prior coursework into their design projects. Finally, student design reports were scored by instructors and students self-reported design mastery, using a common rubric.

Results and Discussion: After completing each integrated project, students demonstrated improved design knowledge and cognizance of integrating prior coursework knowledge into their designs. Students also reported significant confidence gains in four major areas: (1) design process and approach, (2) working with hardware, (3) working with software and interfacing with hardware, and (4) communicating results. Focus group responses support the observed quantitative improvements in student design confidence. Further, instructor scoring of student design reports indicate that design achievement and ability to communicate design improve as students complete additional projects. By implementing and assessing hands-on engineering design project assignments at the sophomore and junior levels, we have improved student design knowledge, confidence, and achievement prior to capstone design. 


\section{Introduction}

An undergraduate biomedical engineering (BME) curriculum should prepare students to approach complex problems confidently. To achieve this, BME programs can offer curricula that help students develop into technically adept engineers, effective communicators, and skilled designers that account for social, economic, and ethical responsibilities. Modern health-related challenges also require innovative thinking and groundbreaking medical technologies, suggesting that these biomedical engineers will continually need to develop design-oriented solutions. The historic shift away from hands-on, machine shop experiences to inclusion of mathematics and science in the curriculum has engaged the engineering community in a renewed emphasis on design [1]. Thus, inductive teaching methods can help instructors guide their students to employ higher cognitive learning toward engineering design [2]-[3]. The inclusion of inductive teaching methods in engineering courses has also been shown to improve communication, teamwork, and application of learning towards real problems [4]-[5], to increase performance on concept inventories [6], and to gain confidence in applying knowledge as students use the iterative, engineering design process when creating a product or prototype [7].

Because engineering prototyping and problem solving require advanced cognition during rapid analysis, synthesis, and evaluation of an evolving design, undergraduate BME curricula generally include laboratory and project components aimed at preparing students for senior capstone. However, students may begin capstone without the knowledge, skills, and confidence required for engineering design success. With these shortcomings in mind, we integrated design experiences across our undergraduate BME curriculum and evaluated student design performance and self-reported confidence toward design throughout. The design experiences developed specifically use the inductive teaching method, project-based learning (PBL), in sophomore (200-) and junior (300-) level BME laboratory courses. PBL is built around studentcentered instruction, and its hallmark is a concrete end-product that has been designed through iterative refinement. Inclusion of four, progressively more challenging design projects into the sophomore and junior year courses provides students opportunity to practice iterative refinement prior to a capstone experience. Further, the literature supports that constructivist principles ground PBL experiences in context-specific learning, active engagement, and sharing of knowledge [8]-[10], all of which we feel are necessary for successful engineering project work. When designed well, PBL experiences can allow students to achieve attainable cognitive growth that can be applied when design challenges become more difficult.

Project-based learning impact on undergraduate academic growth is well documented in the literature; however, few projects compel students to understand and utilize an engineering design process or the Food and Drug Administration (FDA) waterfall diagram [11] to emphasize the BME design process during learning. Examples of PBL in the literature vary in the level of student expectation (e.g., theoretical vs. physical prototype) [12] or connectedness to the BME design process [13]-[14]. In addition to general engineering skills (critical thinking, problem solving, teamwork, communication, etc.), students can benefit from specific skill development (prototyping, computer programming, computational analysis, and testing). Moreover, familiarity with different software tools, programming languages, and testing equipment can make approaching design less intimidating for students. In particular, observed weaknesses in engineering design skills can limit the success of student teams in capstone design. A successful 
capstone team takes an organized approach to design, integrates engineering analysis, and leverages available resources toward the development of a functional prototype. We envision that our curricular interventions at the sophomore and junior levels will ultimately facilitate these behaviors among student capstone teams.

Our work has developed and integrated challenging, hands-on engineering design modules that require student teams to design and deliver functional prototypes in response to relevant biomedical problems. Improving student skill and confidence in approaching design should allow capstone design teams to have more success, particularly during the early phases of projects when building and testing a prototype may be premature. The inclusion of these assignments throughout the BME curriculum should help students improve as decision makers and problem solvers.

\section{Methods}

Context: Students in the undergraduate biomedical engineering program at a Midwestern public university enroll in one required BME laboratory course per semester during the sophomore and junior years. Each of these one-credit courses is tied to a three-credit lecture course, and these courses collectively introduce students to biomechanics, biomeasurements, biomaterials, and cell $\&$ tissue properties. The freshman and senior years of the BME curriculum include significant engineering design components, but design was absent from the middle of the curriculum prior to this intervention. Furthermore, accredited undergraduate engineering programs must demonstrate student ability to identify, formulate, and solve complex engineering problems [15]. Four design projects were created and integrated into BME laboratory courses to address this goal while supporting course-level learning outcomes.

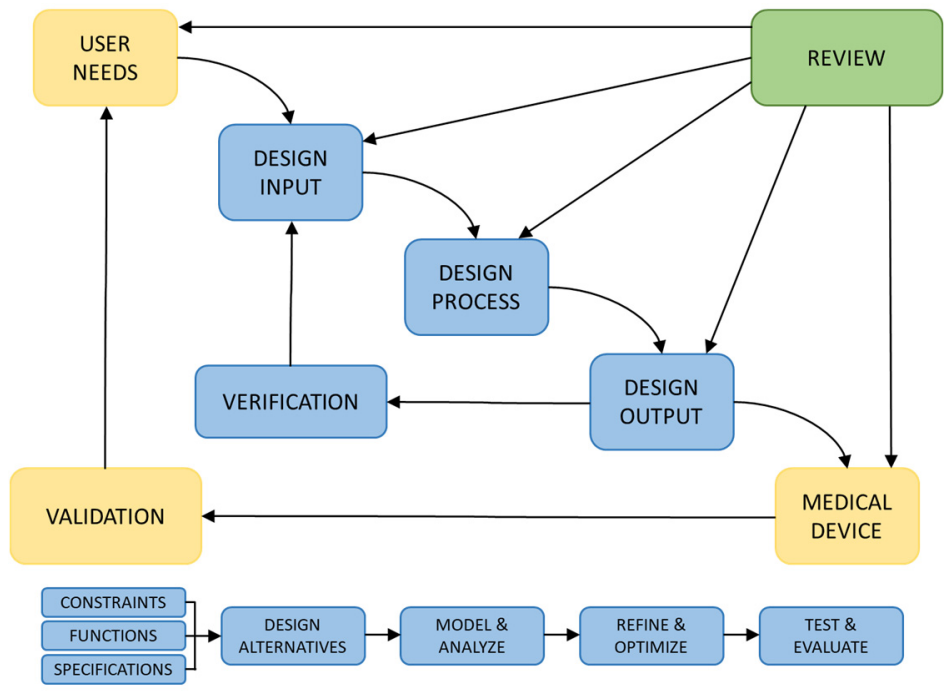

Figure 1: The BME Design Process. The authors adapted the FDA waterfall diagram in order to provide more detail of the design process, design input and output, and verification testing. [11]

BME Design Module: Curricular materials were developed by the authors that highlight the use of the engineering design process in medical device development. This common Design Module was used to build student design vocabulary, differentiate design in biomedical engineering from 
other disciplines, and provide a consistent thread throughout the curriculum. The Design Module was slightly adapted for each course in order to emphasize different parts of the BME design process, some of which were more or less relevant depending on the project. Specifically, the course instructor delivered a roughly 15-minute introduction of medical device design organized around an adapted version of the FDA's waterfall diagram (Figure 1). This was followed by an accessible discussion involving an already approved device that is relevant to the course topics. The instructor then introduced the design project and student teams worked on the projects in parallel with their other laboratory coursework. Students could access both the Design Module and all project files via the course learning management system.

Design Project Sequence: Four engineering design project assignments were developed and integrated into sophomore- and junior-level BME laboratory courses, establishing a continuous design thread spanning the four years of the undergraduate curriculum. Through the sequence of projects, student teams worked to design (1) fracture fixation devices, (2) electromyogram (EMG) controlled motor assemblies, (3) compact spectrophotometers, and (4) programmable drug dosing devices. Students enrolled in 200-level BME laboratory courses completed the projects in teams of 4-5, while students enrolled in 300-level courses were in teams of 3-4. Teams were assigned by the authors, in an effort to balance student ability and personality. Each project culminated with student teams submitting final design reports and demonstrating functional prototypes; these demonstrations were conducted in-person for three projects, while student teams produced videos for the EMG-controlled motor project. The set of design projects also intentionally targeted a multitude of skills relevant to design, including computer-aided design (CAD), finite element analysis (FEA), iteration, prototyping, programming (LabVIEW, MATLAB, and Python), hardware-software integration, and technical communication. Figure 2 summarizes the objectives, design emphases, and targeted skills of the four developed projects. Figure 3 depicts a summary of student artifacts from each projects.

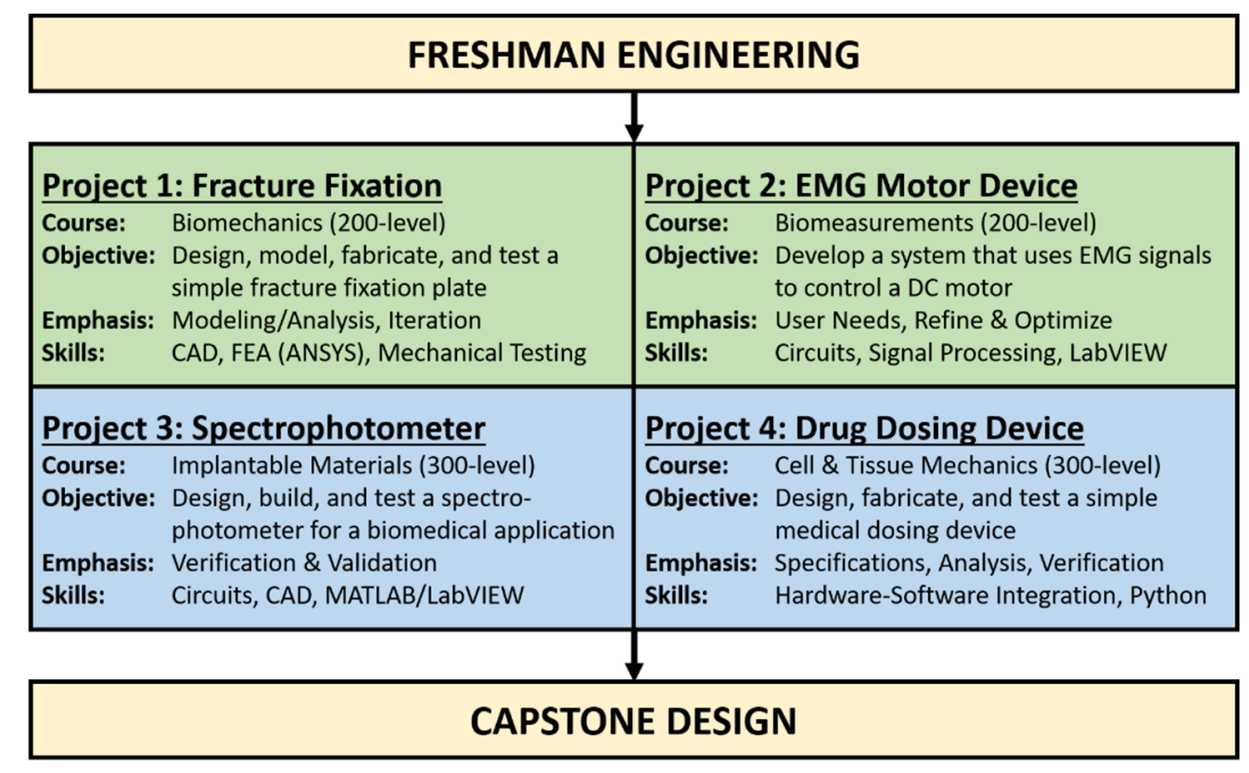

Figure 2: The BME Design Curriculum. The four developed projects, two delivered in the sophomore year and two delivered in the junior year, bridge the design gap that previously existed between freshman and capstone design experiences in the curriculum. Each design project intentionally targets aspects of the

BME design process and provides opportunity to build hands-on, modeling, and programming skills. 


\section{0-level Projects}

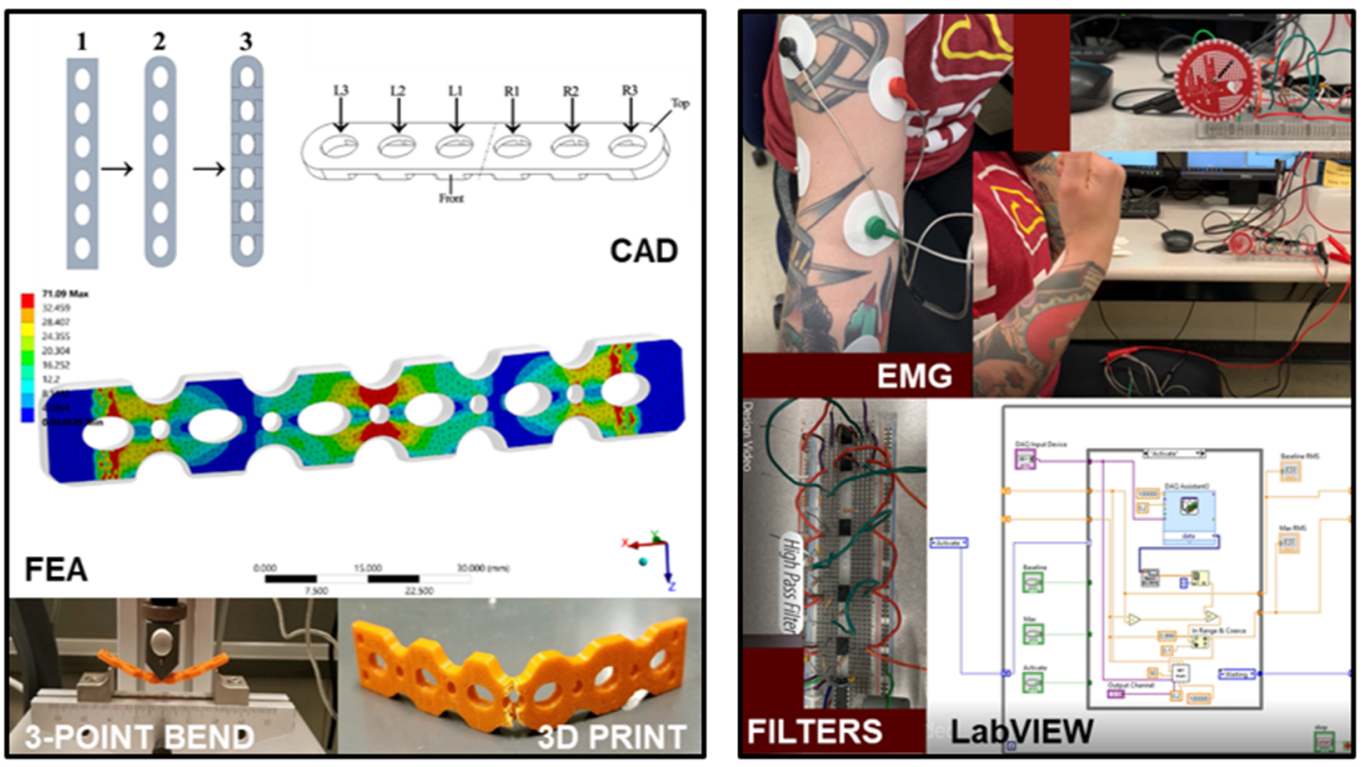

\section{0-level Projects}
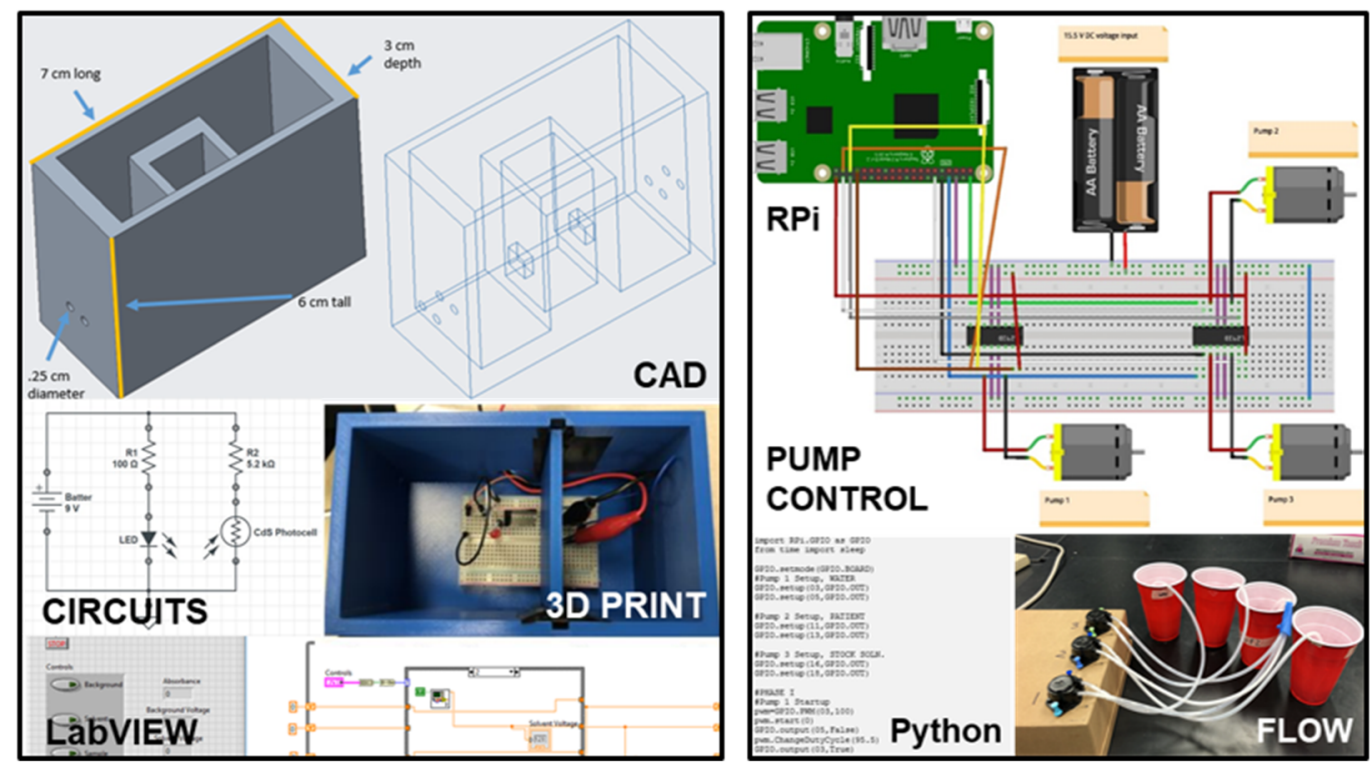

Figure 3: Student Artifacts from BME Design Projects. Artifacts submitted by student teams across the four design projects accentuate the breadth of skills that students develop through these experiences.

Students perform engineering analysis, collect and analyze signals from the body, use CAD and 3D printing to develop prototypes, develop software in multiple programming languages, and work with varied hardware components.

Data Collection and Assessment: A mixed methods approach was employed to assess student design knowledge, design achievement, and confidence approaching design. The data presented here were collected over the course of one academic year (two semesters). Consequently, two separate student populations were tracked. The majority of students who completed the first 200- 
level project also completed the second 200-level project. Similarly, the majority of students who completed the first 300-level project also completed the second 300-level project (but no 200level projects). The authors used a collection of existing, adapted, and new assessment tools to evaluate three total learning outcomes. Unpaired, two-sample Student's t-tests were used to determine statistical significance $(\alpha=0.05)$ for all quantitative comparisons of design knowledge and confidence. The assessment tools are grouped by learning outcome in the following sections.

Outcome 1: Students will demonstrate knowledge of the BME design process

A design quiz (8 questions worth 10 points total) was developed and used to assess student design knowledge and application of this knowledge toward medical device design. Topics covered on the quiz included the BME design process (FDA waterfall diagram [11]), specifications, requirements, constraints, and verification and validation. An example version of this quiz is presented in Appendix A. The quiz was given to students before completing their first design project ("pre"), after completing their first design project ("post"), and after a second design project ("post-post"). Minimal didactic instruction regarding design was included in each course.

Outcome 2: Students will apply engineering design and integrate foundational BME knowledge to develop solutions for design problems

In design reflection surveys, students were asked to identify previous knowledge and coursework that contributed to their designs. The responses were analyzed thematically to identify courses and topics that were identified by multiple students. Final design reports submitted by student teams for each project were scored using an instructor rubric influenced by the American Association of Colleges and Universities (AAC\&U) VALUE Rubrics [16] and the Informed Design Teaching and Learning Matrix [17]. Finally, after each design project, students selfreported design mastery via survey questions aligning with the categories of the instructor rubric. Comparisons between student and faculty assessment of design competency were drawn using design report scoring and student survey responses.

Outcome 3: Students will demonstrate confidence when approaching a design problem Students self-reported their design confidence levels prior to the first design project and after each design project. Students responded to survey questions that asked them to report their perceived self-confidence on a Likert scale (1-not very confident, 3-neutral, 5-very confident) in four categories: (1) approaching design, (2) working with hardware, (3) working with software and interfacing with hardware, and (4) communicating results. Additionally, focus groups were held (including all students in each class) to assess student design confidence going forward and to solicit feedback about the assignments. The campus Center for Teaching and Learning conducted these student focus groups after each project's completion. Finally, students were also asked to rate how worthwhile and how enjoyable they found each project using a reflection grid [18], which ranged from 0-4 in both categories. All survey and focus group questions are included in Appendix B.

\section{Results and Discussion}

Student Design Knowledge: Students engaged in 200-level and 300-level projects demonstrated knowledge gains of the BME design process (Figure 4). Students enrolled in 200-level courses 
exhibited statistically significant design knowledge gains after completing both projects ("postpost"). Students who completed the 300-level projects exhibited significant knowledge gains after completing one project ("post") and maintained these gains through a second semester and project ("post-post"). Notably, by the end of the sophomore year, students exhibited significantly better design knowledge than incoming juniors who had not completed any design projects (denoted by the red asterisk in Figure 4). Further, specific areas of student knowledge gains were identified among 200-level and 300-level students, including the waterfall diagram, design requirements and constraints, and verification and validation $(\mathrm{p}<0.005$ for each).

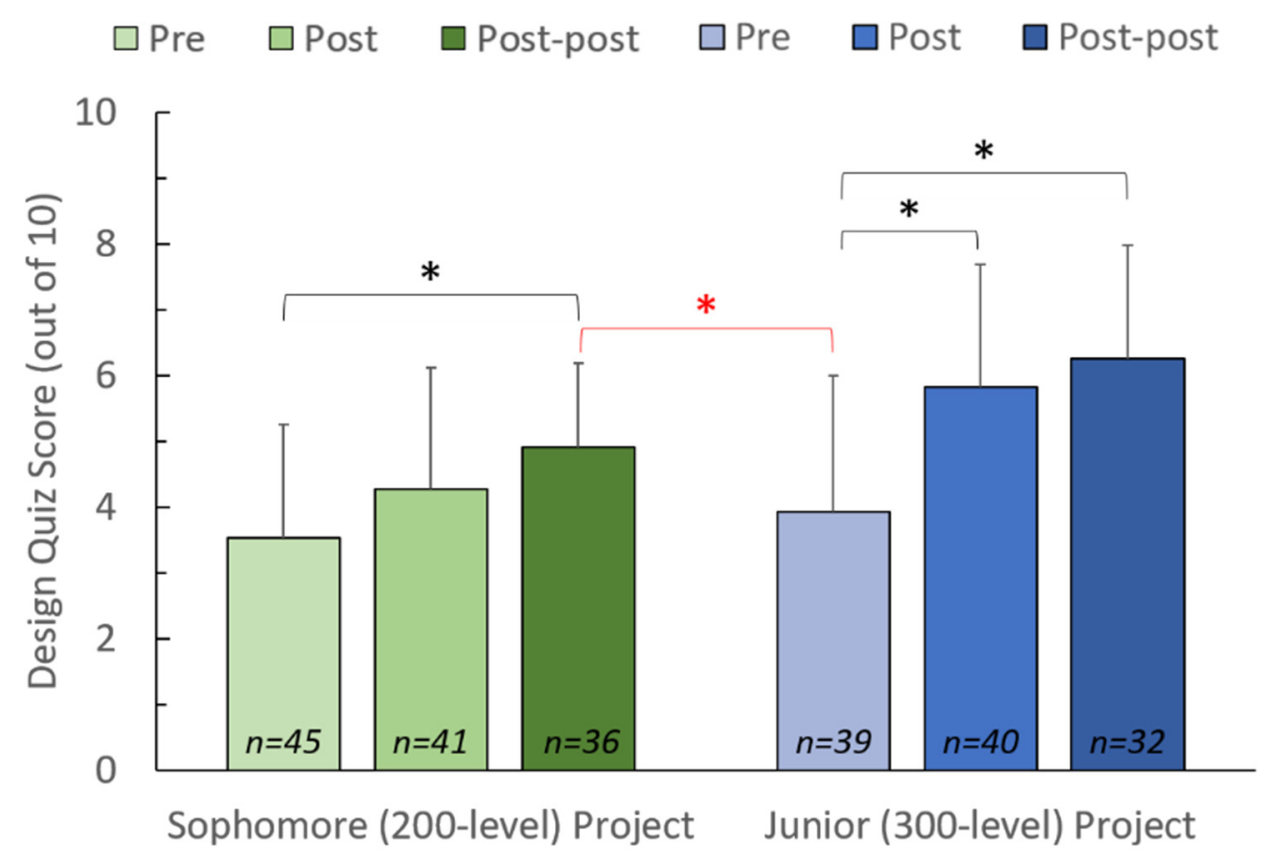

Figure 4: Student Design Knowledge. Mean student performance on a design quiz improves after completing design projects. Asterisks denote statistically significant differences ( $\mathrm{t}$-test, $\alpha=0.05)$. The red comparison indicates that by the end of the sophomore year, students exhibited significantly better design knowledge than incoming juniors who had not completed any design projects.

In addition to gaining new design knowledge, the implemented projects are opportunities for students to apply course knowledge toward hands-on design problems. In response to a qualitative survey question delivered after each design project, students demonstrate cognizance of prior coursework knowledge that they have integrated into their designs. Figure 5 summarizes these data for each project, displaying the percentages of students who identified specific courses and engineering topics that were integral to their designs. The significant extent to which students identify prior coursework as integral to design projects adds to the overall feeling of curricular connectedness, which we as faculty often aspire to. Nonetheless, there remains an opportunity to improve the design projects in this regard, as students minimally identified courses in biology and higher mathematics in their responses. 


\begin{tabular}{|c|c|c|c|c|c|}
\hline & & $\begin{array}{c}\text { Project } 1 \\
(n=23)\end{array}$ & $\begin{array}{c}\text { Project } 2 \\
(n=19)\end{array}$ & $\begin{array}{c}\text { Project } 3 \\
(n=34)\end{array}$ & $\begin{array}{c}\text { Project } 4 \\
(n=27)\end{array}$ \\
\hline \multirow{4}{*}{$\begin{array}{c}\text { BME } \\
\text { Courses }\end{array}$} & Biomeasurements & - & $37 \%$ & $71 \%$ & $48 \%$ \\
\hline & Biomechanics & $48 \%$ & - & - & - \\
\hline & Implantable Materials & - & - & $9 \%$ & $30 \%$ \\
\hline & Biomedical Computing & - & - & - & $7 \%$ \\
\hline \multirow{6}{*}{$\begin{array}{c}\text { Freshman } \\
\text { Courses }\end{array}$} & Biology & - & - & $9 \%$ & - \\
\hline & Calculus & - & $11 \%$ & - & $7 \%$ \\
\hline & Chemistry & - & - & $12 \%$ & $10 \%$ \\
\hline & Coding/MATLAB & $13 \%$ & $5 \%$ & - & $15 \%$ \\
\hline & Design & $13 \%$ & $11 \%$ & - & - \\
\hline & Physics & $30 \%$ & $47 \%$ & $9 \%$ & $7 \%$ \\
\hline \multirow{11}{*}{ Topics } & Circuit design & - & $21 \%$ & $50 \%$ & $56 \%$ \\
\hline & Coding & - & $5 \%$ & - & $19 \%$ \\
\hline & Computer-Aided Design & $35 \%$ & - & - & - \\
\hline & Design Process & $22 \%$ & $37 \%$ & - & $11 \%$ \\
\hline & Differential Equations & - & - & - & $41 \%$ \\
\hline & Fluids, Flow, Pumps & - & - & - & $22 \%$ \\
\hline & Kirchhoff/Ohm's Law & - & $11 \%$ & $6 \%$ & - \\
\hline & LabVIEW & - & $11 \%$ & $38 \%$ & - \\
\hline & MATLAB & $17 \%$ & $11 \%$ & - & $4 \%$ \\
\hline & Spectroscopy/Beer's Law & - & - & $27 \%$ & - \\
\hline & Stress, Strain, Forces & $43 \%$ & - & - & - \\
\hline
\end{tabular}

Figure 5: Integration of Coursework Knowledge into Design. Responding to a qualitative survey question after completing each design project, students identified knowledge from prior courses (BME and pre-BME/Freshman Courses) and specific engineering topics that were integrated into their designs.

Darker shades of green and blue indicate increased student response and hyphens indicate no student responses.

Student Design Confidence: Before and after completing each project, students self-reported confidence levels on a Likert Scale (1-not very confident, 3-neutral, 5-very confident) in four areas: (1) design process and approach, (2) working with hardware, (3) working with software and interfacing with hardware, and (4) communicating results. The results of these surveys are depicted in Figure 6. After completing one design project, both 200- and 300-level students reported significant confidence gains in all four areas $(\mathrm{p}<0.05$ for each). In some cases, students reported additional confidence gains after completing a second design project. Focus group responses from the first (fracture fixation) and fourth (drug dosing) projects support the observed quantitative improvements in student design confidence. Focus groups were also held for the second (EMG-motor) and third (spectrophotometer) projects, but student comments from these sessions are omitted here for the sake of brevity. Focus group moderators from the campus Center for Teaching and Learning summarized and sorted student comments into three categories: little to no improvement, moderate improvement, and large improvement in selfreported student confidence. Comments are categorized and summarized in Table 1. 

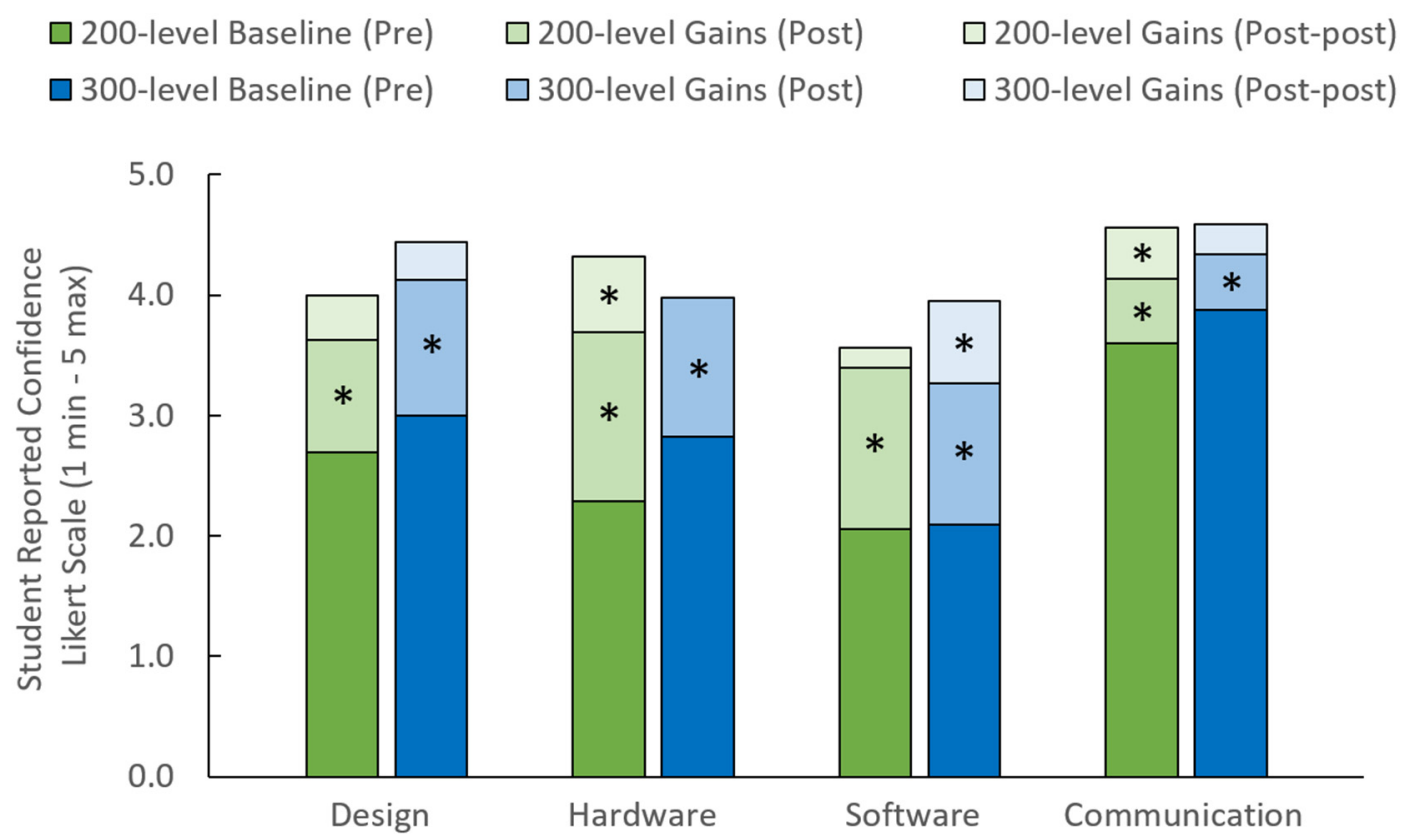

Figure 6: Student Design Confidence. Students self-reported design confidence in four areas, before and after each design project. Asterisks on "Post" bars denote statistically significant increases when compared to "Pre" values, and asterisks on "Post-post" bars denote further significant increases as compared to "Post" values (t-tests, $\alpha=0.05$ ).

Student Design Achievement: Levels of design achievement - the successful application and documentation of the engineering design process - were assessed in two ways: students selfassessed design mastery via survey after each design project and the authors scored all student design reports using the adapted Informed Design rubric [17]. Scoring of student design reports indicates that design achievement and ability to communicate design improve as students complete additional design projects; however, student self-assessment of design mastery remains remarkably consistent across the four projects. Student self-assessment considerably outpaces faculty perception for the first three projects in the curriculum, but the scores fall more in line for the fourth and final project. It is possible that students sincerely perceive their design abilities to be consistent; however, this contrasts with perceived gains in design confidence. It is also possible that the questions themselves bias the responses toward consistent values, given that students are less able than faculty to evaluate skill development over the course of a whole program rather than a single course.

For the purposes of drawing comparisons between student self-assessment and faculty scoring of design reports, the categories from the adapted Informed Design rubric [17] were condensed into five total categories: (1) Research \& Problem Formation, (2) Idea Generation \& Representation, (3) Iteration \& Experimentation, (4) Design Reflection, and (5) Communication of Design. Faculty and student assessment scores for each project are depicted in Figure 7. Although these comparisons relate individual student self-assessment to faculty assessment of team documents, the divergence is striking, nonetheless. 
Table 1: Categorized Summary of Student Focus Group Responses from Project 1 and Project 4

Focus Group Question: Having completed the design project, has your confidence in approaching a design problem changed? Explain your answer.

\section{Project 1 (Fracture Fixation) Focus Group ( $\mathrm{n}=12$ teams)}

Large improvement in confidence

- Compared to beginning of semester, we are a lot more comfortable using the approach to a design project.

- Having this experience helped increase confidence. Working through the iterative process flowchart helped introduce us to design and revision process.

- Yes, more practice on this process helped.

- The process is less daunting, so yes, more confidence. (multiple citations)

Moderate improvement in confidence

- Somewhat yes, but working with ANSYS was confusing and complicated. (multiple citations)

- All are in agreement that confidence level has changed because of the great amount of freedom and independence given.

Little or no improvement in confidence

- Overall, confidence did not increase because the process was messy. We did not [have] formulas that would have been helpful. The presentation of this project was not realistic to research/design problems. A lot of wasted times because of varying guidelines.

- No, if we were given more information on what the objective was all along with better instructions at how to approach the problem.

- Still unsure of specific steps in design problem, but still used them. (multiple citations)

Project 4 (Drug Dosing) Focus Group ( $\mathrm{n}=11$ teams)

Large improvement in confidence (4 teams)

- Project more clearly defined and had better structure, easier to know what was expected.

- Raspberry Pi, circuit analysis, motor driver chip, and pump characterization improved significantly. Need more confidence with Python though.

Moderate improvement in confidence (5 teams)

- $\quad$ Learned how to find resources and what questions to ask

- Practice on the design process to make design more efficient compared to previous semester.

Little or no improvement in confidence ( 2 teams)

- Already knew the software and many concepts of the project.

- We weren't focused on the design process so that project was just straight forward. 


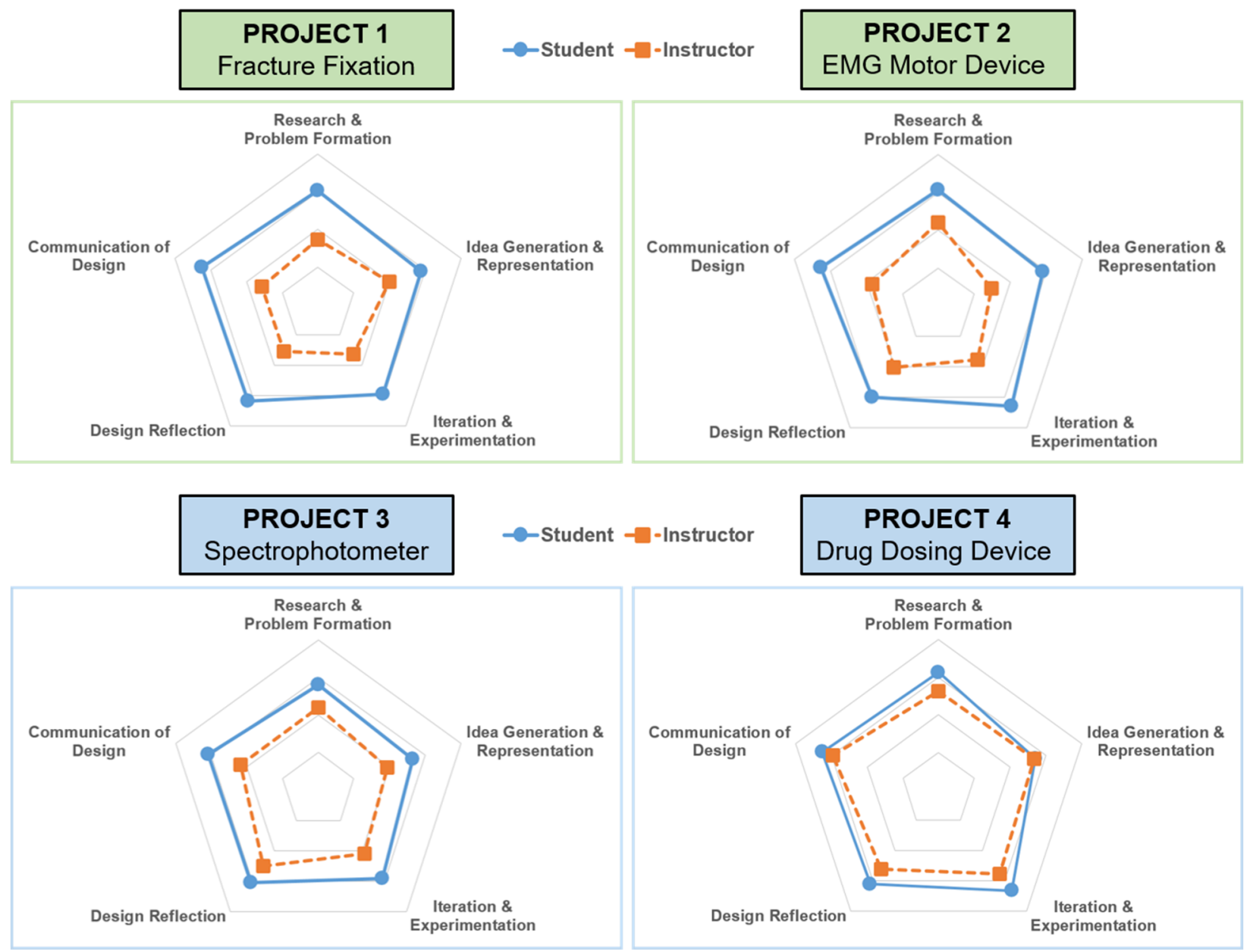

Figure 7: Comparison of Student and Faculty Assessment of Design Abilities. Student selfassessment of design abilities (blue markers) remains mostly consistent in surveys performed after each design project. Faculty assessment of student team design reports (orange markers) changes considerably across the four projects. Both student and faculty scores are reported on a scale from 0 (center of each plot) to 4 (outermost grey line on each plot).

Student Reception: After the completion of each design project, students were asked to rate how worthwhile and how enjoyable they found the experience. When combining the results from the four projects, a majority of students $(67 \%)$ found the experiences enjoyable to some degree, and a larger majority of students $(80 \%)$ found the experiences worthwhile to some degree. In fact, $62 \%$ of students found the projects to be both worthwhile and enjoyable. These student responses are depicted in two heat maps in Figure 8, one each for the 200- and 300-level projects. The generally positive responses to the projects are encouraging, but there is room for improvement. Better delivery of the projects, enhanced instructional tools, and improved team management could all contribute to student learning and enjoyment.

Conclusions and Outlook: The addition of newly developed design projects into the second and third years of a BME curriculum has been mostly successful. After completing these projects, students gain design knowledge, perceive growing self-confidence in approaching new design situations, and improve their abilities to apply and document the engineering design process. Further, a significant majority of students have found the projects to be both worthwhile and 
enjoyable, and evidence suggests that students apply knowledge from across the curriculum when developing solutions. Due to the multidisciplinary nature of biomedical engineering, faculty in these programs must strive to create such curricular connections to bridge the gap between medicine, science, and engineering. The expanded focus on design in the curriculum has created opportunities to explore engineering analysis, prototyping, and design testing prior to the capstone experience. By emphasizing different aspects of design process, varying project deliverables, and providing consistent instructor feedback across four courses, we have implemented a stepwise approach to building student design confidence.
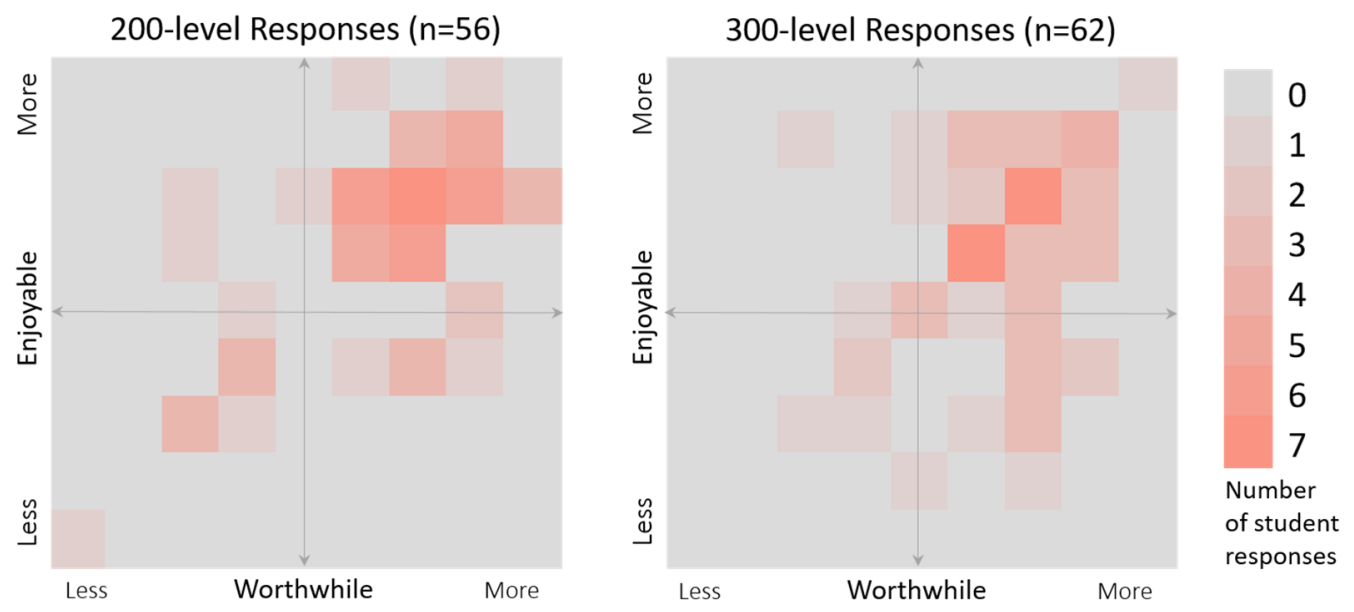

Figure 8: Student Reception of Design Projects. The majority of students who completed design projects at both the 200- and 300-levels found the experiences to be both worthwhile and enjoyable.

This paper summarizes student growth and feedback in response to the first implementation of the integrated design projects, spanning one academic year. The amount and quality of student feedback we have received, both via survey and anecdotally, and our own observations have prompted us to enact improvements to the projects going forward. We have highlighted a few of our plans in the list below.

- Although the projects are meant to be mostly self-guided by student teams, we need to develop tutorials to better guide student learning of new skills (e.g., use of finite element analysis software, physical computing in Python).

- Student teams enjoyed making video demonstrations for the EMG Motor Device project, and the quality of submissions was above our expectation. We are considering moving to more video-based deliverables, both to eliminate the challenge of scheduling in-person demonstrations and to provide outlets for creative technical communication.

- We provided design kits to each student team at the beginning of each project. This model has been successful, overall, but tracking of kit components has been challenging. We are implementing a more organized system of labeling and check-in/-out of kits to ease the burden on teaching assistants and protect our investment in parts and equipment.

- More work remains to make seamless the integration of the projects into existing lab courses. As with any new curricular intervention, some students have identified these projects as "extra work" or as somehow separate from the course. Further practice in the delivery of the assignments should alleviate this issue, but we are also working to ensure strong connections with course topics and training course instructors on design instruction and assessment. 
In spite of the student learning gains and overall positive reaction to the new curriculum, there remains ample room for improvement with regards to both the delivery of the curriculum and the methods we employ to assess student growth. From a curricular standpoint, the most significant challenges exist because the projects are delivered to student teams, rather than to individuals. Consequently, our efforts are subject to all of the limitations and pitfalls that generally affect team assignments. It is certainly possible that the gains we see are not shared equally among all students, given the vagaries of student team dynamics. With respect to assessment, the most significant limitation is our reliance on student self-perception. Students perceive growing design confidence as they complete projects, but we have yet to produce objective data to support this. Conversely, students are remarkably consistent in rating their own design abilities across the curriculum, while we observe significant improvements as students advance through our program. Moving forward, we aim to develop instruments or adapt published instruments that more objectively measure student self-efficacy toward design [19] for use in our program and, more generally, in the context of biomedical engineering education. Bandura proposes four main sources of efficacy information: performance accomplishments, vicarious experience, verbal persuasion, and physiological states [20]. We aim to contribute to an understanding of how student design confidence relates to such described mechanisms for changes in self-efficacy.

\section{Acknowledgments}

The authors would like to thank the IUPUI Center for Teaching and Learning for their support via the Curriculum Enhancement Grant (CEG) and for moderating focus groups.

\section{References}

[1] J.E. Froyd, P.C. Wankat, and K.A. Smith, "Five Major Shifts in 100 Years of Engineering Education," Proceedings of the IEEE, vol 100, pp. 1344-1360, May 2012.

[2] M.J. Prince and R.M. Felder, "Inductive Teaching and Learning methods: Definitions, Comparisons, and Research Bases," Journal of Engineering Education, pp. 123-138, Apr 2006.

[3] J.C. Perrenet, P.A.J. Bouhuijs and J.G.M.M. Smits, "The Suitability of Problem-based Learning for Engineering Education: theory and practice," Teaching in Higher Education, vol 5(3), pp. 345-358, 2000.

[4] J.E. Mills and D.F. Treagust, "Engineering Education-Is Problem-Based or Project-Based Learning the Answer?" Australasian Journal of Engineering Education, pp. 2-16, 2002.

[5] De Los Rios-Carmenado I., Rodriguez Lopez F., Perez Garcia C., "Promoting Professional Project Management Skills in Engineering Higher Education: Project-Based Learning (PBL) Strategy," International Journal of Engineering Education, vol 31(1B), 2015, pp. 184-198.

[6] S. Freeman, S.L. Eddy, M. McDonough, M.K. Smith, N. Okoroafor, H. Jordt, and M.P. Wenderoth, "Active learning increases student performance in science, engineering and mathematics, PNAS, vol 111(23), pp. 8410-8415, 2014. 
[7] A. Aditomo, P. Goodyear, A. Bliuc, and R.A. Ellis, "Inquiry-based learning in higher education: principal forms, educational objectives, and disciplinary variations", Studies in Higher Education, vol 38(9), pp. 1239-1258, 2013. DOI: 10.1080/03075079.2011.616584

[8] D. Kokotsaki, V. Menzies, and A. Wiggins, "Project-based learning: A review of the literature," Improving Schools, vol 19(3), pp. 267-277, 2016.

[9] C.L. Dym, A.M. Agogino, O. Eris, D.D. Frey, and L.J. Leifer, "Engineering Design Thinking, Teaching, and Learning", Journal of Engineering Education, pp. 103-120, 2005.

[10] Lee J.S., Blackwell S., Drake J., Moran K.A., “Taking a Leap of Faith: Redefining Teaching and Learning in Higher Education Through Project-Based Learning," Interdisciplinary Journal of Problem-Based Learning, vol 8(2), 2014, pp. 19-34.

[11] "Design Control Guidance," Food and Drug Administration [Online]. Available: https://www.fda.gov/downloads/MedicalDevices/DeviceRegulationandGuidance/GuidanceDocu ments/ucm070642.pdf.

[12] T.D. Giorgio and S.P. Brophy, "Challenge-Based Learning in Biomedical Engineering: A Legacy Cycle for Biotechnology," Proceedings of the American Society for Engineering Education Annual Conference \& Exposition, 2001.

[13] J. Yao and S. Warren, "Stimulating Student Learning with a Novel 'In-House' Pulse Oximeter Design," Proceedings of the American Society for Engineering Education Annual Conference \& Exposition, 2005.

[14] K. Bougot-Robin, J. Paget, S.C. Atkins, and J.B. Edel, "Optimization and Design of an Absorbance Spectrometer Controlled Using a Raspberry Pi To Improve Analytical Skills," Journal of Chemical Education, pp. 1232-1240, Mar 2016.

[15] ABET Engineering Accreditation Commission. 2020. Criteria for accrediting engineering programs: Effective for evaluation during the 2019-20 accreditation cycle. Baltimore, MD: Accreditation Board for Engineering and Technology.

[16] T. Rhodes, Assessing outcomes and improving achievement: Tips and tools for using rubrics. Washington, DC: Association of American Colleges and Universities, 2010.

[17] D.P. Crismond and R.S. Adams, "The Informed Design Teaching and Learning Matrix," Journal of Engineering Education, vol 101, no 4, pp. 738-797, Oct 2012.

[18] Reflection Workshop Workbook, Consortium to Promote Reflection in Engineering Education, Sept 2017.

[19] A. R. Carberry, H.-S. Lee, and M. W. Ohland, "Measuring Engineering Design SelfEfficacy," Journal of Engineering Education, vol. 99, no 1, pp. 71-79, Jan. 2010.

[20] A. Bandura, "Self-efficacy: Toward a unifying theory of behavioral change," Psychol. Rev, vol 84, no 2, pp. 191-215, 1977. 


\section{Appendix A: Design Quiz}

\section{BME Engineering Design Module - Design Quiz}

1. Draw a classic waterfall diagram that describes the engineering design process, identifying the key design phases, activities, and the relationships between them. (3 pts)

2. What are the characteristics of a well written design requirement? (1 pt)

3. Within the context of engineering design, define constraint. (1 pt)

4. Within the context of engineering design, define specification. (1 pt)

5. Tests that provide objective evidence that specified requirements have been fulfilled. The statement above best defines: (1 pt)
a. Verification Testing
b. Validation Testing
c. Both
d. Neither

6. A trace matrix summarizes: (1 pt)
a. Design Requirements
b. Verification Testing
c. Validation Testing
d. All of the above

Answer questions 7 \& 8 considering the simple medical device design scenario*.

Simple Medical Device Design Scenario

Consider the design of a wound dressing (used to protect open wounds and promote healing) for use in burn wards in resource-limited settings (e.g., sub-Saharan Africa).

7. Which of the following statements represents a specification that is relevant to the simple medical device design scenario? ( $1 \mathrm{pt}$ )

a. The wound dressing must be made of cotton.

b. The wound dressing must have sufficient tensile strength $(100 \mathrm{kPa})$.

c. The wound dressing must cost less than $\$ 5$ to manufacture.

d. None of the above

8. Propose a test that should be performed on the design and state whether the proposed test represents an example of verification or validation. $(1 \mathrm{pt})$

* Different scenarios were used each time the quiz was delivered, so students never saw the same scenario more than once. 


\section{Appendix B: Design Survey \& Focus Group Questions}

\section{Survey Questions (Pre- / Post-)}

1. On a scale of 1 to 5 ( 1 - not very confident, 3 - neutral, 5 - very confident), how confident do you feel in each area listed below?
a. Design Process \& Approach
b. Hardware \& Physical Parts
c. Software \& Interfacing with Hardware
d. Communicating Results (Written and/or Oral)

\section{Survey Questions (Post-)}

1. Score on a scale of 1-4 (1 - Beginning Designer Behavior, 4 - Informed Designer Behavior) how you and your team approached the different stages of BME Design throughout this project. Each stage has defined in words informed and beginning designer behavior. If a design stage was skipped or intentionally left out, please mark as N/A.

* For a list of these behaviors, please see Crismond and Adams (2012) [17]

2. What knowledge (design process or fundamental math/science) did you apply to the project? For example, if the knowledge applied during this project is from a previous physics or math course, list the concept and course name or number.

3. Using the plot below, identify one intersection point that describes your perception of the BME Design Activity. Choose a node on the intersection point with which you identify.

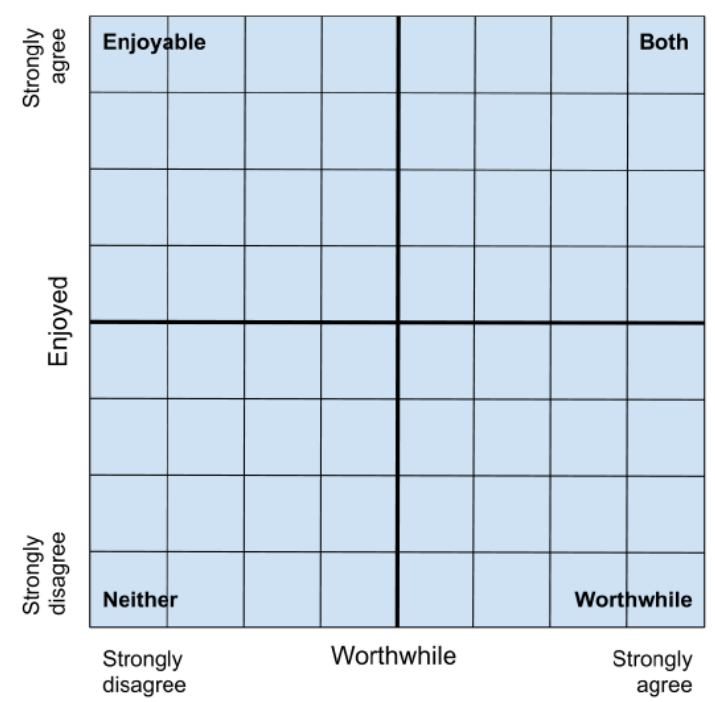

\section{Focus Group Questions}

1. Comment on the aspects of working on a team that affected your design process. Were parts of the design process more/less challenging because it was a team project?

2. Having completed the design project, has your confidence in approaching a design problem changed? If so, how?

3. What improvements could be made to the engineering design project to assist your learning? What specific strategies do you suggest for producing these improvements? 